\title{
Short-term Effects of Ambient Air Pollution on Emergency Department Visits for Asthma: An Assessment of Effect Modification by Prior Allergic Disease History
}

\author{
Juhwan Noh', Jungwoo Sohn', Jaelim Cho², Seong-Kyung Cho ${ }^{3}$, Yoon Jung Choi ${ }^{4}$, Changsoo Kim ', Dong Chun Shin ${ }^{1,5}$ \\ ${ }^{1}$ Department of Preventive Medicine, Yonsei University College of Medicine, Seoul; ${ }^{2}$ Department of Occupational and Environmental Medicine, \\ Gachon University Gil Hospital, Incheon; ${ }^{3}$ Department of Medical Informatics and Biostatistics, Yonsei University College of Medicine, Seoul; ${ }^{4} \mathrm{Health}$ \\ Insurance Review and Assessment Service, Seoul; Institute for Environmental Research, Yonsei University College of Medicine, Seoul, Korea
}

Objectives: The goal of this study was to investigate the short-term effect of ambient air pollution on emergency department (ED) visits in Seoul for asthma according to patients' prior history of allergic diseases.

Methods: Data on ED visits from 2005 to 2009 were obtained from the Health Insurance Review and Assessment Service. To evaluate the risk of ED visits for asthma related to ambient air pollutants (carbon monoxide [CO], nitrogen dioxide $\left[\mathrm{NO}_{2}\right]$, ozone $\left[\mathrm{O}_{3}\right]$, sulfur dioxide $\left[\mathrm{SO}_{2}\right]$, and particulate matter with an aerodynamic diameter $\left.<10 \mu \mathrm{m}\left[\mathrm{PM}_{10}\right]\right)$, a generalized additive model with a Poisson distribution was used; a single-lag model and a cumulative-effect model (average concentration over the previous 1-7 days) were also explored. The percent increase and 95\% confidence interval (Cl) were calculated for each interquartile range (IQR) increment in the concentration of each air pollutant. Subgroup analyses were done by age, gender, the presence of allergic disease, and season.

Results: A total of 33751 asthma attack cases were observed during the study period. The strongest association was a $9.6 \%$ increase $(95 \% \mathrm{Cl}, 6.9 \%$ to $12.3 \%)$ in the risk of ED visits for asthma per IQR increase in $\mathrm{O}_{3}$ concentration. IQR changes in $\mathrm{NO}_{2}$ and $\mathrm{PM}_{10}$ concentrations were also significantly associated with ED visits in the cumulative lag 7 model. Among patients with a prior history of allergic rhinitis or atopic dermatitis, the risk of ED visits for asthma per IQR increase in $\mathrm{PM}_{10}$ concentration was higher (3.9\%; $95 \% \mathrm{Cl}, 1.2 \%$ to $6.7 \%)$ than in patients with no such history.

Conclusions: Ambient air pollutants were positively associated with ED visits for asthma, especially among subjects with a prior history of allergic rhinitis or atopic dermatitis.

Key words: Air pollution, Asthma, Emergencies, Time series analysis, Effect modifier, Korea

Received: April 9, 2016 Accepted: September 8, 2016

Corresponding author: Changsoo Kim, MD, PhD

50-1 Yonsei-ro, Seodaemun-gu, Seoul 03722, Korea.

Tel: +82-2-2228-1880, Fax: +82-2-392-8133

E-mail: preman@yuhs.ac

This is an Open Access article distributed under the terms of the Creative Commons Attribution Non-Commercial License (http://creativecommons.org/licenses/bync/4.0/) which permits unrestricted non-commercial use, distribution, and reproduction in any medium, provided the original work is properly cited.

\section{INTRODUCTION}

In the Republic of Korea (hereafter Korea), asthma was the fifth leading cause of disease burden in 2007 [1]. The hospital admission rate for asthma in 2011 was two times greater than the overall average for Organization for Economic Cooperation and Development countries [2]. Pediatric asthma corresponds to the largest burden of disease in children, and the prevalence of asthma has steadily increased from 1998 to the pres- 
ent [3]. Furthermore, the incidence of adult asthma has rapidly increased, and the burden of this disease seems to have continually increased in Korea [4].

Clark et al. [5] reported that recent increases in prevalence are thought to be caused not only by genetic factors, but by exposure to environmental factors. Evidence indicates that air pollution exacerbates preexisting asthma and contributes to the development of asthma [6-10]. According to studies of associations between air pollutants and asthma exacerbation, increases in mortality and emergency department visits can be triggered by $10-\mu \mathrm{m}$ particulate matter, nitrogen dioxide $\left(\mathrm{NO}_{2}\right)$, and ozone $\left(\mathrm{O}_{3}\right)$ [11-13].

The findings of a recent study suggested that eczema and rhinitis are strongly associated with symptomatic atopic asthma in adults in middle age [14]. However, until recently, few studies have explored the effect modification by prior allergic disease, including atopic dermatitis (AD), allergic rhinitis (AR), and asthma, on the association between asthma exacerbation and air pollutants. Furthermore, the asthma index forecast system, which was developed as a preventive strategy and has been in operation since 2009, does not consider prior allergic diseases [15]

In this study, we assessed the short-term effect of ambient air pollution on emergency department (ED) visits due to asthma in Seoul, after stratification by demographic characteristics, prior allergic disease, and season, in order to analyze the effect modification of these factors on the association between air pollutant levels and asthma exacerbation.

\section{METHODS}

Using data collected by the Health Insurance Review and Assessment Service (HIRA), we constructed a study population of individuals who visited an ED in Seoul at least once from January 1, 2005 to December 31, 2009. ED visits were identified using the International Classification of Diseases, 10th revision codes for asthma (J45-46), and the number of daily patient visits was calculated. For each participant, the anonymized secondary data comprised all individualized claims data, including participants' age and gender. The first visits of individual patients who had multiple ED encounters during the study period were classified as the subgroup without a history of asthma. The presence of a history of asthma history and prior allergic disease among asthma patients was defined as any outpatient visits or admissions with a discharge diag- nosis code for asthma, AR (J30), or AD (L20) from 2000 until the ED visit. Four seasons were identified: spring (March to May), summer (June to August), fall (September to November), and winter (December to February).

Air pollution data for $\mathrm{O}_{3}$ (parts per billion [ppb]), carbon monoxide (CO, parts per million [ppm]), $\mathrm{NO}_{2}(\mathrm{ppb})$, sulfur dioxide $\left(\mathrm{SO}_{2}, \mathrm{ppb}\right)$, and particulate matter of median aerometric diameter less than $10 \mu \mathrm{m}\left(\mathrm{PM}_{10}, \mu \mathrm{g} / \mathrm{m}^{3}\right)$ were obtained from 27 ambient automated fixed-site monitoring stations at 25 districts in Seoul maintained by the Research Institute of Public Health and Environment of the Seoul metropolitan government. Daily mean concentrations of $\mathrm{CO}, \mathrm{NO}_{2}, \mathrm{SO}_{2}$, and $\mathrm{PM}_{10}$ and 8-hour maximum $\mathrm{O}_{3}$ were calculated as the average of hourly measured data from 2005 to 2009. The Korea Meteorological Administration provided daily average data, including temperature $\left({ }^{\circ} \mathrm{C}\right)$, relative humidity $(\%)$, and vapor pressure $(\mathrm{hPa})$ measured by a station at Jongno-gu in Seoul from 2005 to 2009 . The total number of measurements was 1826 , and the interquartile ranges (IQRs) used in our analyses were $\mathrm{O}_{3}$, 22.6 ppb; $\mathrm{CO}, 0.3$ ppm; $\mathrm{NO}_{2}, 18.3$ ppb; $\mathrm{SO}_{2}$, 2.8 ppb; $\mathrm{PM}_{10}, 35.5$ $\mu \mathrm{g} / \mathrm{m}^{3}$; temperature, $17.7^{\circ} \mathrm{C}$; relative humidity, $21.9 \%$; and vapor pressure, $12.6 \mathrm{hPa}$.

In the present study, associations between ED visits for asthma and ambient air pollution concentrations were estimated using generalized additive models with a Poisson distribution [16]. A generalized additive model is a semi-parametric model, in which a linear predictor depends on the sum of smooth functions of covariates to control for potential confounding [17].

The models contained the daily number of ED visits for asthma as the dependent variable, ambient air pollution concentrations as independent variables, and covariates, including the day of the week, holidays, time trends, and daily mean meteorological measurements. The day of the week, holidays, and pollutant concentration were modeled as linear effects and others as a cubic spline variable to adjust for seasonal and temporal effects; time trends were measured with 6 degrees of freedom (df) per year, temperature with $6 \mathrm{df}$, and relative humidity and vapor pressure with $3 \mathrm{df}$, which were chosen a priori based on previous studies $[18,19]$.

$$
\begin{aligned}
\log [E(Y)]= & \beta_{0}+\beta_{1} \text { ambient air pollution }+\beta_{2} \text { day of week }+\beta_{3} \text { holiday } \\
& +S(\text { time trend, } d f=6)+S(\text { temperature }, d f=6) \\
& +S(\text { relative humidity, } d f=3)+S(\text { vapor pressure, } d f=3)
\end{aligned}
$$

The percent increases in ED visits and their 95\% confidence 
intervals (Cls) were reported for the short-term effects of each IQR increment for each pollutant concentration. In order explore lag effects, we used a single-lag model and a cumulative-effect model. The effect of an ambient air pollutant on a given day was estimated using the concentration on the same day or on all previous 3 days (lag $0, \operatorname{lag} 1, \operatorname{lag} 2$, or $\operatorname{lag} 3$, respectively) The cumulative effect of mean pollutant concentrations during the 1 to 7 previous days prior to the ED visits was used to estimate the effect (e.g., lags 0-3 used the mean concentrations of $\operatorname{lag} 0, \operatorname{lag} 1, \operatorname{lag} 2$, and $\operatorname{lag} 3$ ).

To explore the effect modification among subgroups, participants were stratified by gender, age in years $(<2,2-5,6-14$, $15-39,40-64$, and $\geq 65$ ), prior allergic disease (with no history of allergic disease, with any history of allergic disease, with a history of asthma, or with a history of $A D$ or $A R$ ), and season. The presence of statistically significant differences between effect estimates across the strata of a potential effect modifier was determined by calculating $95 \% \mathrm{Cls}$ [20]. All analyses were performed using SAS version 9.4 (SAS Institute Inc., Cary, NC, USA) or R version 3.2.1 (Comprehensive R Archive Network: http://cran.r-project.org).

\section{RESULTS}

Table 1 summarizes the characteristics of the ED visits. The study population consisted of 27146 patients who made 33751 ED visits due to asthma. Table 2 lists the 24-hour mean concentrations of ambient air pollutants and meteorological variables. The temporal variation of asthma ED visits, daily mean concentrations of air pollutants, temperature, relative humidity, and vapor pressure is shown in Supplemental Figure 1. The Pearson correlation coefficient between pollutant con- centrations and meteorological variables was shown in Supplemental Table 1.

Figure 1 shows the estimated percent increase in asthma ED visits for each IQR change in air pollutants using single lags from the same day to day 3 and cumulative lags from the given day to day 7. The strongest association per IQR increase in

Table 1. Emergency department visits for asthma, Seoul, Korea, 2005-2009

\begin{tabular}{|c|c|c|c|c|c|c|}
\hline \multirow{2}{*}{ Characteristics } & \multirow{2}{*}{$\begin{array}{c}\text { Total visits } \\
\text { n (\%) }\end{array}$} & \multicolumn{5}{|c|}{ Daily visits } \\
\hline & & Mean \pm SD & 5th & 50th & 95th & IOR \\
\hline \multicolumn{7}{|l|}{ Gender } \\
\hline Men & 15526 (46.0) & $10 \pm 5.3$ & 4 & 9 & 20 & 6 \\
\hline Women & $18225(54.0)$ & $8.5 \pm 4.1$ & 3 & 8 & 16 & 5 \\
\hline \multicolumn{7}{|l|}{ Age (y) } \\
\hline$<2$ & $4131(12.2)$ & $2.3 \pm 2$ & 0 & 2 & 6 & 2 \\
\hline $2-5$ & $6820(20.2)$ & $3.7 \pm 2.9$ & 0 & 3 & 10 & 3 \\
\hline $6-14$ & $4524(13.4)$ & $2.5 \pm 2.7$ & 0 & 2 & 8 & 2 \\
\hline $15-39$ & $5138(15.2)$ & $2.8 \pm 2.1$ & 0 & 2 & 7 & 3 \\
\hline $40-64$ & $6247(18.5)$ & $3.4 \pm 2$ & 1 & 3 & 7 & 3 \\
\hline$\geq 65$ & $6891(20.4)$ & $3.8 \pm 2.3$ & 1 & 3 & 8 & 3 \\
\hline \multicolumn{7}{|l|}{ Prior allergic disease } \\
\hline Without any history & $12765(37.8)$ & $7 \pm 4$ & 2 & 6 & 14 & 5 \\
\hline$A D$ or $A R$ history & $4325(12.8)$ & $2.4 \pm 1.9$ & 0 & 2 & 6 & 2 \\
\hline Asthma history & 16661 (49.4) & $9.1 \pm 4.5$ & 3 & 9 & 17 & 5 \\
\hline \multicolumn{7}{|l|}{ Season } \\
\hline Spring & 8712 (25.8) & $18.9 \pm 6.3$ & 10 & 18 & 31 & 8 \\
\hline Summer & 6012 (17.8) & $13.1 \pm 4.9$ & 6 & 13 & 22 & 7 \\
\hline Fall & $10586(31.4)$ & $23.3 \pm 10.1$ & 11 & 21 & 42 & 12 \\
\hline Winter & $8441(25.0)$ & $18.7 \pm 7.4$ & 10 & 17 & 33 & 9 \\
\hline Total & 33751 (100) & $18.5 \pm 8.5$ & 8 & 17 & 34 & 9 \\
\hline
\end{tabular}

$S D$, standard deviation; IQR, interquartile range; $A D$, atopic dermatitis; $A R$, allergic rhiniti; Spring, March to May; Summer, June to August; Fall, September to November; Winter, December to February.

Table 2. Distributions of pollutants and meteorological variables, Seoul, Korea, January 2005 to December 2009

\begin{tabular}{|c|c|c|c|c|c|c|c|c|c|c|}
\hline \multirow{2}{*}{ Pollutant } & \multirow{2}{*}{ Units } & \multicolumn{5}{|c|}{ Daily variation } & \multicolumn{4}{|c|}{ Seasonal variation (Mean \pm SD) } \\
\hline & & Mean \pm SD & 5th & 50th & 95th & IOR & Spring & Summer & Fall & Winter \\
\hline $\mathrm{O}_{3}$ (8-h maximum) & $\mathrm{ppb}$ & $31.7 \pm 17.0$ & 8.1 & 28.9 & 63.0 & 22.6 & $72.3 \pm 60.6$ & $46.7 \pm 26.0$ & $48.6 \pm 28.5$ & $62.5 \pm 32.2$ \\
\hline CO (daily mean) & ppm & $0.6 \pm 0.3$ & 0.3 & 0.5 & 1.1 & 0.3 & $41.1 \pm 13.2$ & $42.7 \pm 18.6$ & $27.3 \pm 12.3$ & $17.1 \pm 7.7$ \\
\hline $\mathrm{NO}_{2}$ (daily mean) & $\mathrm{ppb}$ & $36.3 \pm 12.7$ & 18.6 & 34.9 & 59.2 & 18.3 & $0.6 \pm 0.2$ & $0.4 \pm 0.1$ & $0.6 \pm 0.2$ & $0.8 \pm 0.3$ \\
\hline $\mathrm{SO}_{2}$ (daily mean) & $\mathrm{ppb}$ & $5.7 \pm 2.5$ & 3.1 & 5.0 & 10.7 & 2.8 & $5.7 \pm 2.3$ & $4.2 \pm 1.0$ & $4.9 \pm 1.9$ & $7.8 \pm 2.7$ \\
\hline $\mathrm{PM}_{10}$ (daily mean) & $\mu \mathrm{g} / \mathrm{m}^{3}$ & $57.6 \pm 38.9$ & 18.1 & 50.2 & 119.6 & 35.5 & $38.7 \pm 12.2$ & $28.7 \pm 8.7$ & $35.2 \pm 11.9$ & $40.7 \pm 13.4$ \\
\hline Temperature (daily mean) & ${ }^{\circ} \mathrm{C}$ & $12.9 \pm 10.2$ & -4.3 & 14.6 & 26.6 & 17.7 & $12.4 \pm 5.9$ & $24 \pm 2.8$ & $15.2 \pm 6.5$ & $-0.3 \pm 4.3$ \\
\hline Relative humidity & $\%$ & $60.8 \pm 14.8$ & 36.4 & 61.4 & 85.0 & 21.9 & $54.8 \pm 15.2$ & $71.1 \pm 12.1$ & $62.5 \pm 12.0$ & $54.1 \pm 12.9$ \\
\hline Vapor pressure & $\mathrm{hPa}$ & $11.3 \pm 7.9$ & 1.9 & 9.0 & 26.1 & 12.6 & $8.2 \pm 3.7$ & $21.3 \pm 4.7$ & $11.8 \pm 5.3$ & $3.5 \pm 1.7$ \\
\hline
\end{tabular}

SD, standard deviation; IQR, interquartile range; Spring, March to May; Summer, June to August; Fall, September to November; Winter, December to February; $\mathrm{O}_{3}$, ozone; $\mathrm{CO}$, carbon monoxide; $\mathrm{NO}_{2}$, nitrogen dioxide; $\mathrm{SO}_{2}$, sulfur dioxide; $\mathrm{PM}_{10}$, particulate matter with an aerodynamic diameter $<10 \mu \mathrm{m}$. 


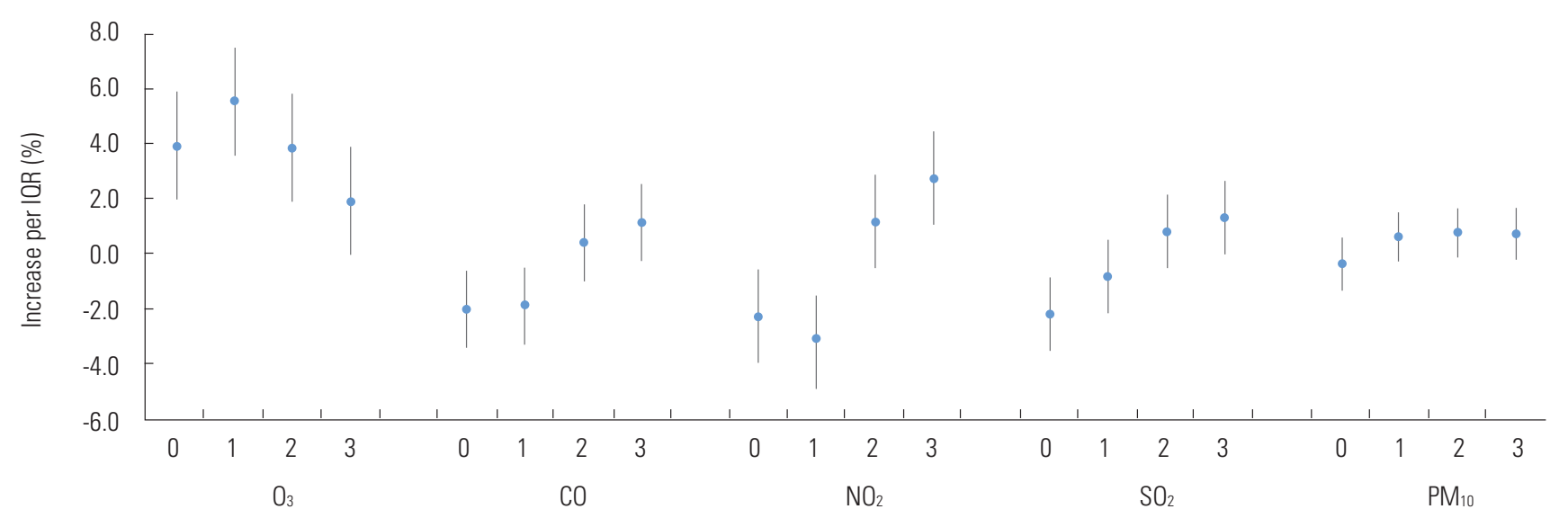

Single lag (d)

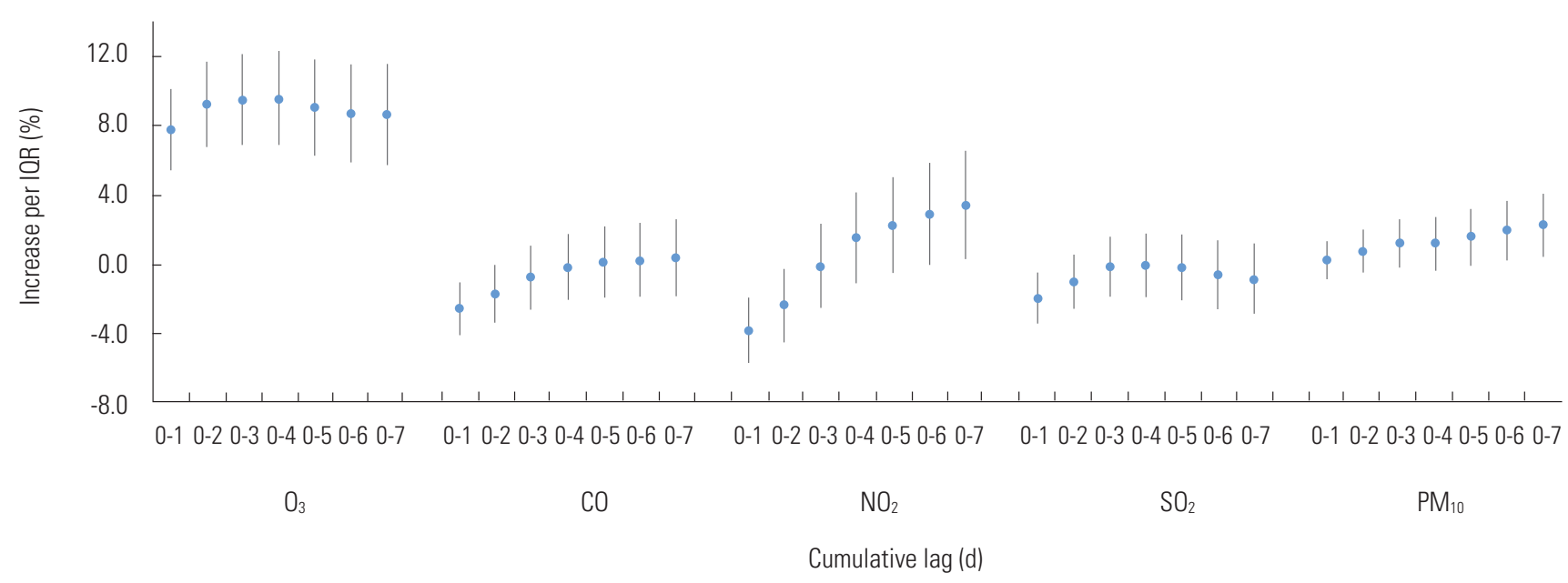

B

Figure 1. Changes in asthma emergency department visits with interquartile range (IQR) increases in ambient pollutants. (A) Single-lag model. (B) Cumulative-effect model (lags 0-3 used the mean concentrations of lag 0, lag 1, lag 2, and lag 3). $\mathrm{O}_{3}$, Ozone; CO, carbon monoxide; $\mathrm{NO}_{2}$, nitrogen dioxide; $\mathrm{SO}_{2}$, sulfur dioxide; $\mathrm{PM}_{10}$, particulate matter with an aerodynamic diameter $<10 \mu \mathrm{m}$.

air pollutant exposure was observed for $\mathrm{O}_{3}$ exposure; a $5.6 \%$ increase $(95 \% \mathrm{Cl}, 3.6 \%$ to $7.5 \%)$ was found in the lag 1 model, and a $9.6 \%$ increase $(95 \% \mathrm{Cl}, 6.9 \%$ to $12.3 \%)$ was found in the in cumulative lag 1 model. $\mathrm{O}_{3}$ exhibited a positive association with asthma ED visits for all lag periods. An IQR change in the $\mathrm{PM}_{10}$ concentration was significantly associated with ED visits in cumulative lag models 5,6 , and $7(2.3 \% ; 95 \% \mathrm{Cl}, 0.5 \%$ to 4.1\%). $\mathrm{NO}_{2}$ was also significantly associated with asthma $\mathrm{ED}$ visits in the lag 3 model $(2.7 \% ; 95 \% \mathrm{Cl}, 1.0 \%$ to $4.5 \%)$ and the cumulative lag 7 model (3.4\%; $95 \% \mathrm{Cl}, 0.4 \%$ to $6.6 \%)$. However, for $\mathrm{CO}, \mathrm{NO}_{2}$, and $\mathrm{SO}_{2}$ in the lag 0 , lag 1, and cumulative lag 1 models, an increase in air pollutants was negatively associated with the risk of $E D$ visits.

After stratification of ED visits by gender, age, season, and prior history of allergic disease, effect modification was observed (Figures 2-4). Among men, the highest risk for asthma
ED visits was observed for $\mathrm{O}_{3}$ in the cumulative lag 3 model (9.0\%; $95 \% \mathrm{Cl}, 5.5 \%$ to $12.6 \%)$. Among women, the association between $\mathrm{ED}$ visits and $\mathrm{O}_{3}$ exposure in the cumulative lag 7 model was the strongest $(15.0 ; 95 \% \mathrm{Cl}, 10.5 \%$ to $19.6 \%)$. Women had a statistically significantly higher risk than men after an IQR change in $\mathrm{O}_{3}$ in the cumulative lag 5 and cumulative lag 7 models ( $p<0.05$ and $p<0.01$, respectively). IQR increases of all pollutants were found to have the strongest associations with $E D$ visits during spring. The risk of ED visits for asthma with exposure to $\mathrm{O}_{3}, \mathrm{CO}, \mathrm{SO}_{2}$, and $\mathrm{PM}_{10}$ was strongest in the cumulative lag 7 model, and that for $\mathrm{SO}_{2}$ and $\mathrm{PM}_{10}$ was statistically significantly higher in spring than in summer and winter, while the risk for $\mathrm{O}_{3}$ was higher in spring than in fall. For $\mathrm{NO}_{2}$ exposure, the highest risk was observed in the cumulative lag 5 model, while the risk in the cumulative lag 7 model was statistically significantly higher in spring than in summer. 

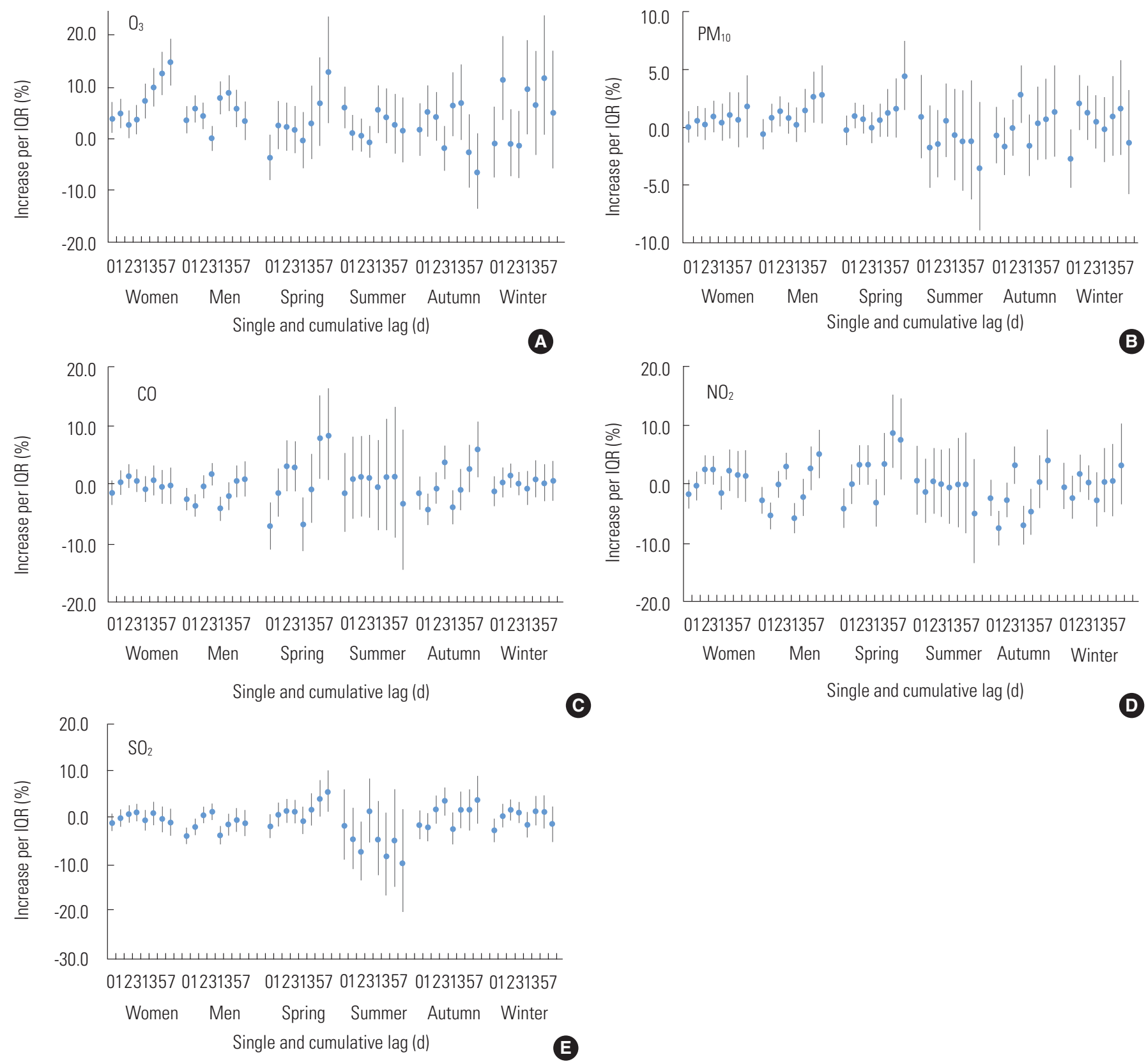

Figure 2. Percent increases in asthma emergency department (ED) visits with an interquartile range (IQR) increases in ambient pollutants after stratification for gender and season. For all strata, single-lag exposure for the day of the visit and 1,2, and 3 days prior to the day of the visit were described as the first four digits $(0,1,2$, and 3 , respectively). Cumulative lagged exposure, the mean concentrations from the day of visit to all subsequent days, were described as the last four digits $(1,3,5$, and 7 , referring to cumulative lag 1, 3, 5, and 7, respectively). The IQR was $22.6 \mathrm{ppb}$ for $\mathrm{O}_{3}, 0.3 \mathrm{ppm}$ for $\mathrm{CO}, 18.3 \mathrm{ppb}$ for $\mathrm{NO}_{2}, 2.8 \mathrm{ppb}$ for $\mathrm{SO}_{2}$, and $35.5 \mu \mathrm{g} / \mathrm{m}^{3}$ for PM $\mathrm{PM}_{10}$. Blue dots indicate the percent increase in asthma ED visits, and bars indicate $95 \%$ confidence intervals. Spring, March to May; Summer, June to August; Fall, September to November; Winter, December to February; $\mathrm{O}_{3}$, Ozone; $\mathrm{PM}_{10}$, particulate matter with an aerodynamic diameter $<10 \mu \mathrm{m} ; \mathrm{CO}$, carbon monoxide; $\mathrm{NO}_{2}$, nitrogen dioxide; $\mathrm{SO}_{2}$, sulfur dioxide.

In the summer, ED visits were significantly associated with $\mathrm{O}_{3}$ (lag 0 and cumulative lag 1), and in the lag 0 model, the risk associated with $\mathrm{O}_{3}$ exposure was higher than in spring. In the fall, the risk of ED visits increased after exposure to IQR increases in $\mathrm{CO}, \mathrm{NO}_{2}, \mathrm{SO}_{2}$ and $\mathrm{PM}_{10}$ in the lag 3 model. In winter, in the lag 1, cumulative lag 1, and cumulative lag 5 models, 

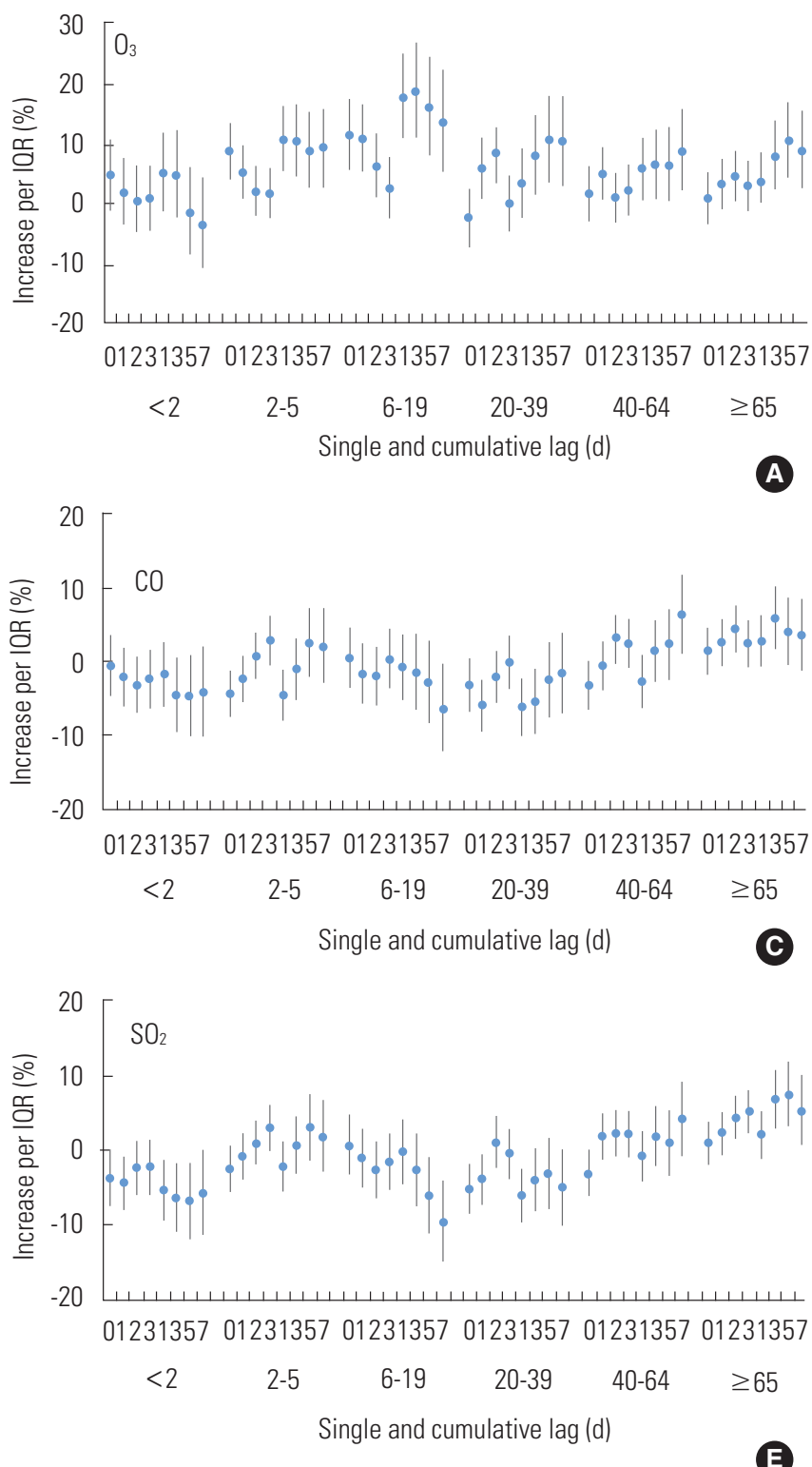

Figure 3. Percent increase in asthma emergency department (ED) visits with interquartile range (IQR) increases in ambient pollutants ( $\mathrm{A}: \mathrm{O}_{3}, \mathrm{~B}: \mathrm{PM}_{10}, \mathrm{C}: \mathrm{CO}, \mathrm{D}: \mathrm{NO}_{2}$, and $\mathrm{E}: \mathrm{SO}_{2}$ ) after stratification for age group. For all strata, single-lag exposure for the day of the visit and 1, 2, and 3 days prior to the day of the visit were described as the first four digits $(0,1,2$, and 3 , respectively). Cumulative lagged exposure, the mean concentrations from the day of visit to all subsequent days, were described as the last four digits $\left(1,3,5\right.$, and 7 , referring to cumulative lag 1, 3, 5, and 7, respectively). The interquartile IQR was $22.6 \mathrm{ppb}$ for $\mathrm{O}_{3}, 0.3 \mathrm{ppm}$ for $\mathrm{CO}, 18.3 \mathrm{ppb}$ for $\mathrm{NO}_{2}, 2.8 \mathrm{ppb}$ for $\mathrm{SO}_{2}$, and $35.5 \mu \mathrm{g} / \mathrm{m}^{3}$ for $\mathrm{PM}_{10}$. Blue dots indicate the percent increase in asthma ED visits, and bars indicate $95 \%$ confidence intervals. $\mathrm{O}_{3}$, ozone; $\mathrm{PM}_{10}$, particulate matter with an aerodynamic diameter $<10 \mu \mathrm{m} ; \mathrm{CO}$, carbon monoxide; $\mathrm{NO}_{2}$, nitrogen dioxide; $\mathrm{SO}_{2}$, sulfur dioxide.

IQR changes in $\mathrm{O}_{3}$ concentration increased the risk of asthma ED visits; the risk in the lag 1 model was significantly higher than in summer, and the risk in the cumulative lag 5 model was statistically higher than in fall. Among all age groups, the strongest effect for $\mathrm{O}_{3}$ exposure was observed in the cumula-
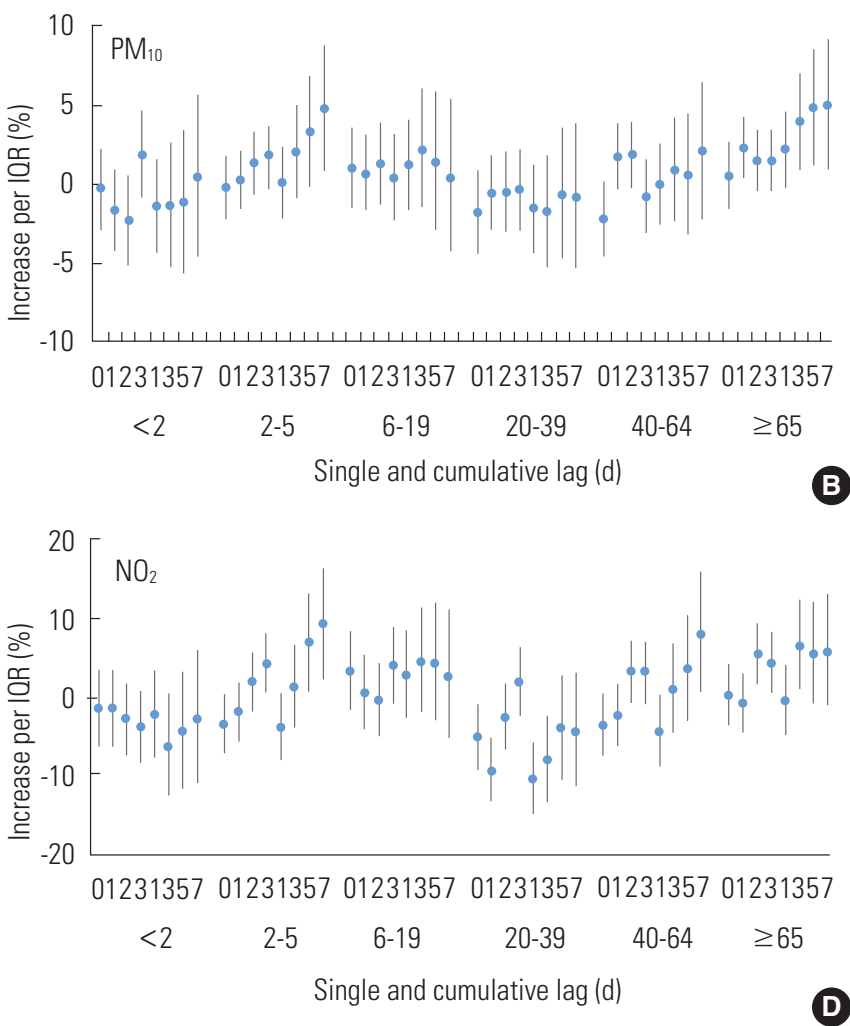

D tive lag 3 model $(26.9 \% ; 95 \% \mathrm{Cl}, 11.1 \%$ to $18.8 \%)$ among individuals 6-19 years of age, and the discrepancy with other age groups was statistically significant. Similar findings were found for the risk of asthma $\mathrm{ED}$ visits for $\mathrm{NO}_{2}$ exposure in the cumulative lag 7 model (16.5\%; $95 \% \mathrm{Cl}, 2.2 \%$ to $9.1 \%$ ) among individ- 

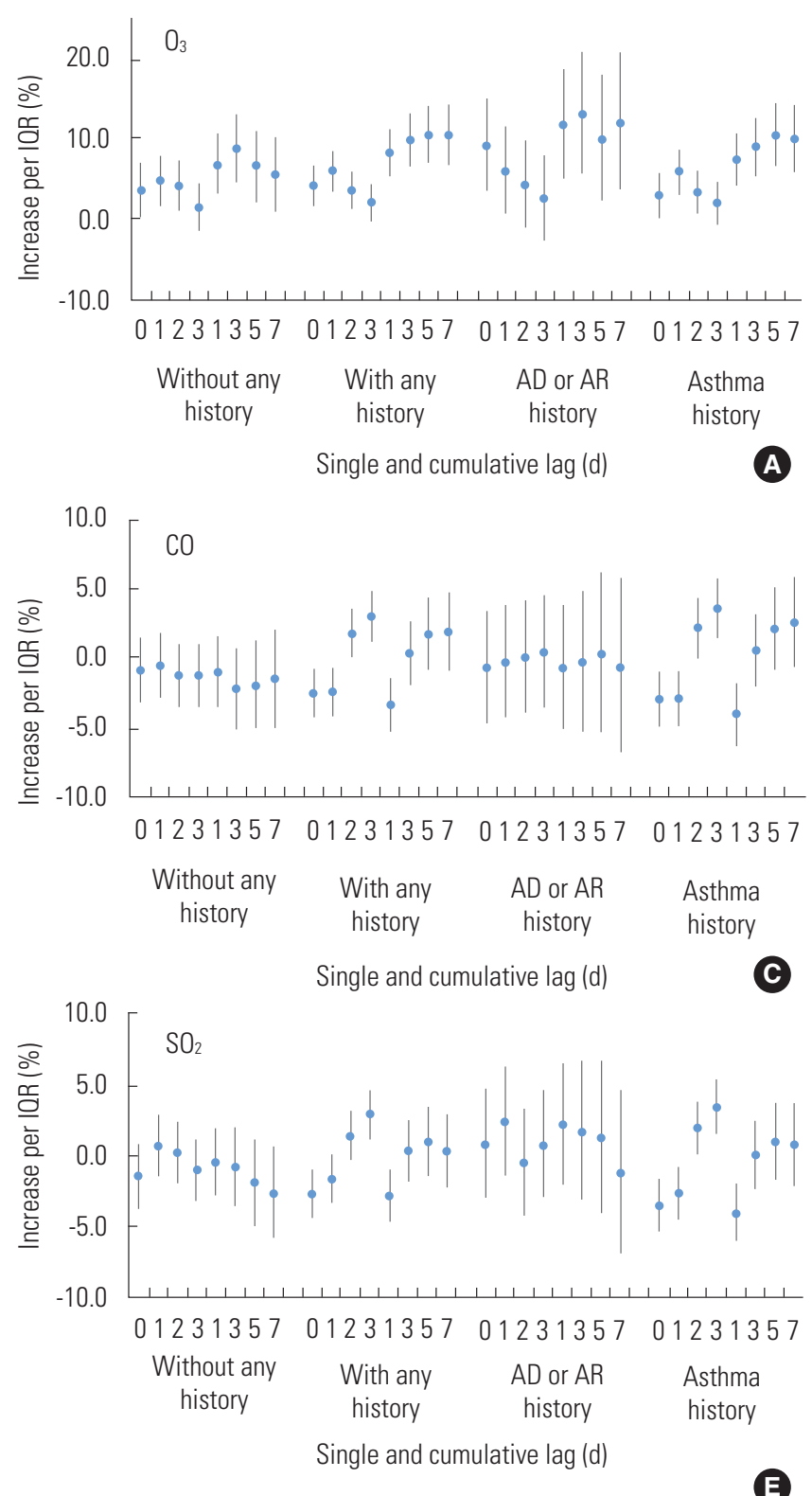

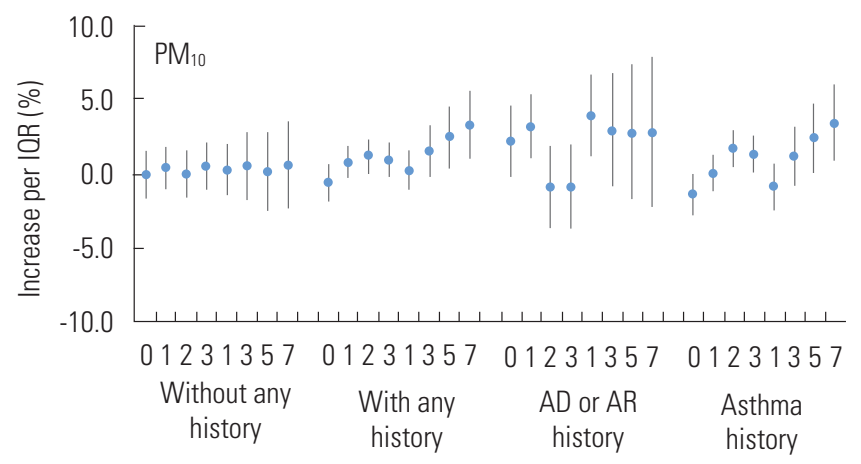

Single and cumulative lag (d)

B

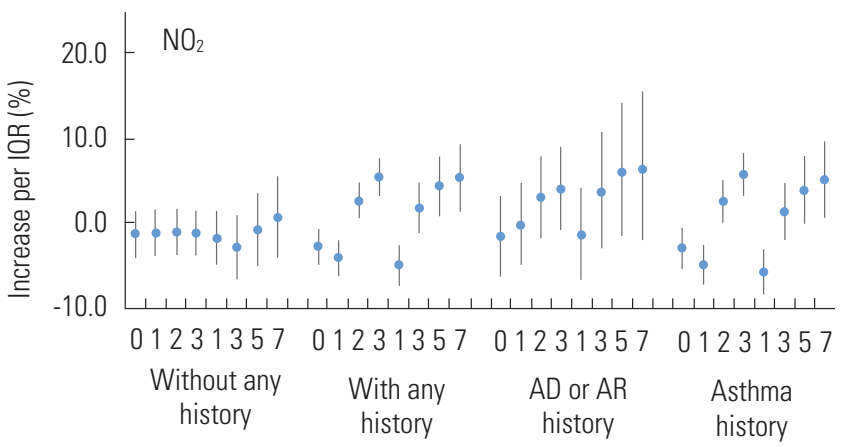

Single and cumulative lag (d)

D

Figure 4. Percent increases in asthma emergency department visits with interquartile range (IQR) increases in ambient pollutants $\left(\mathrm{A}: \mathrm{O}_{3}, \mathrm{~B}: \mathrm{PM}_{10}, \mathrm{C}: \mathrm{CO}, \mathrm{D}: \mathrm{NO}_{2}\right.$, and $\left.\mathrm{E}: \mathrm{SO}_{2}\right)$ after stratification for prior allergic history. For all strata, single-lag exposure for the day of the visit and 1,2, and 3 days prior to the day of the visit were described as the first four digits $(0,1,2$, and 3 , respectively). Cumulative lagged exposure, the mean concentrations from the day of visit to all subsequent days, were described as the last four digits $\left(1,3,5\right.$, and 7, referring to cumulative lag 1, 3, 5, and 7, respectively). The IQR was $22.6 \mathrm{ppb}$ for $\mathrm{O}_{3}, 0.3 \mathrm{ppm}$ for $\mathrm{CO}, 18.3$ ppb for $\mathrm{NO}_{2}, 2.8 \mathrm{ppb}$ for $\mathrm{SO}_{2}$, and $35.5 \mu \mathrm{g} / \mathrm{m}^{3}$ for $\mathrm{PM}_{1}$. Blue dots indicate the percent increase in asthma $\mathrm{ED}$ visits, and bars indicate $95 \%$ confidence intervals. $A D$, atopic dermatitis; $A R$, allergic rhinitis; $\mathrm{O}_{3}$, ozone; $\mathrm{PM}_{10}$, particulate matter with an aerodynamic diameter $<10 \mu \mathrm{m} ; \mathrm{CO}$, carbon monoxide; $\mathrm{NO}_{2}$, nitrogen dioxide; $\mathrm{SO}_{2}$, sulfur dioxide.

uals two to five years of age, for $\mathrm{SO}_{2}$ exposure in the cumulative lag 5 model $(7.3 \%, 95 \% \mathrm{Cl}, 3.1 \%$ to $11.7 \%)$ and $\mathrm{PM}_{10}$ exposure in the cumulative lag 7 model $(5.0 \% ; 95 \% \mathrm{Cl}, 1.0 \%$ to 9.3\%) among those $\geq 65$ years age, and for $\mathrm{CO}$ exposure in the cumulative lag 7 model $(6.2 \% ; 95 \% \mathrm{Cl}, 1.0 \%$ to $11.6 \%)$ among those aged 40-64 years. Although the difference between subgroups was statistically non-significant, the largest risk of ED visits for asthma per IQR increase of $\mathrm{O}_{3}$ concentration was 
observed among patients with a history of AD or AR in the cumulative lag 3 model (13.1\%; $95 \% \mathrm{Cl}, 5.8 \%$ to $21.0 \%)$. The risk for each IQR increase of $\mathrm{PM}_{10}$ concentration was statistically significantly higher in the cumulative lag 1 model $(3.9 \%$; $95 \%$ $\mathrm{Cl}, 1.2 \%$ to $6.7 \%)$ and in the lag 1 model $(3.1 \% ; 95 \% \mathrm{Cl}, 1.0 \%$ to $5.3 \%$ ) among participants with a previous history of AR or $A D$ than in participants without any history of allergic disease or with a history of asthma ( $p<0.05$ for both). Among the participants with a prior history of asthma, the association between $\mathrm{ED}$ visits for asthma and $\mathrm{NO}_{2}, \mathrm{CO}$, and $\mathrm{SO}_{2}$ was greatest in the lag 3 model ( $p<0.01$ for all).

\section{DISCUSSION}

In our study, IQR increases in the concentration of ambient air pollutants were associated with increased ED visits for asthma. In particular, among subjects with a prior history of $A D$ or $A R$, the risk was higher than for those without such histories. Among pollutants, the strongest association per IQR increase in air pollutants exposure was observed for $\mathrm{O}_{3}$ in the cumulative lag 1 model. IQR changes in $\mathrm{PM}_{10}$ and $\mathrm{NO}_{2}$ concentrations were significantly associated with ED visits in the cumulative lag 7 model. The findings of our results are consistent with those of previous studies [10,21-24]. Implausible negative associations of certain pollutants with asthma ED visits were observed. One possible explanation of the negative associations is that $\mathrm{CO}, \mathrm{NO}_{2}$, and $\mathrm{SO}_{2}$ were highly negatively correlated with $\mathrm{O}_{3}$; thus, relatively high levels of $\mathrm{CO}, \mathrm{NO}_{2}$, and $\mathrm{SO}_{2}$ could be indicators of low levels of $\mathrm{O}_{3}$, resulting in less asthma ED visits.

In our study, after stratification of subjects by demographic characteristics, seasons, and prior allergic disease, the highest risk for $\mathrm{O}_{3}$ exposure was observed in the cumulative lag 3 model (26.9\%; $95 \% \mathrm{Cl}, 11.1 \%$ to $18.8 \%$ ) among individuals 6-19 years of age; this was a statistically significant effect in comparison with other age groups. Women patients had a statistically significantly higher risk than men after $\mathrm{O}_{3}$ exposure, with a lagged effect. Much epidemiological evidence regarding different patterns of associations between air pollution and respiratory health for men and women has been reported; however, the results have not been consistent with regard to gender discrepancies [25]. Gender differences in airway behavior are influenced by three biological determinants: dimensional (structural and functional) relationships, hormonal determinants, and immunological determinants [26]. In the current study, the risk associated with $\mathrm{O}_{3}$ exposure was higher for women than men, although the risks associated with exposure to other ambient pollutants was statistically similar for both genders. These findings might be attributed to dimensional determinants; that is, that women have, on average, a shorter airway and smaller lungs than men. In our study, for all ambient air pollutants, the risk showed a bimodal distribution, with peaks in the age groups of 2-19 years and $\geq 65$ years. Of all age groups, the largest association between $\mathrm{O}_{3}$ exposure and ED visits was observed among patients aged 6-19 years, while that for $\mathrm{NO}_{2}$ exposure was found among participants 2-5 years of age. It is likely that children are likely to engage in more outdoor activities and to be more affected by exposure to ambient pollutants. The highest risks per IQR change in $\mathrm{SO}_{2}$ and $\mathrm{PM}_{10}$ concentrations were observed in participants $\geq 65$ years of age, and the highest risk per IQR change in CO concentration was observed in individuals between 40-64 years of age. The younger age group (2-19 years old) tended to have the strongest association between ED visits for asthma and IQR increases in all pollutants. A plausible interpretation of those results might be that children are still in the process of lung growth and the development of defense mechanisms. The results of the present study are similar to those of the most recent systematic review and meta-analysis [27]. Among the subgroup aged $<6$ years, the associations were statistically significant; however, the patterns of asthma ED visits among those age groups ( $<2$ and 2-5 years) might be biased due to misclassification. Asthma is difficult to diagnose, and for this age group, a clinical diagnosis is necessary because it is not possible to perform a pulmonary function test and many other medical conditions induce cough and wheezing. For example, respiratory virus infections, not asthma, are another common cause of wheezing in children aged $<2$ years, and the number of ED visits for asthma might therefore be overestimated [3]. Children ( $<2$ years) also spend more than half the day indoors, such that the association is slightly weaker than for other groups. In those over 45 years of age, although the differential diagnosis is relatively easier than children, the diagnosis of asthma can also be problematic as the condition can be confused with chronic obstructive pulmonary disease (chronic bronchitis) or heart failure (left ventricle). In terms of seasonal effects, associations with air pollutants had a greater magnitude during spring (March to May). In spring, all pollutants were found to have the largest association with ED visits for asthma. Stieb et al. [28] reported that a greater association was observed during the warm season (April to September). 
In summer, IQR increases in $\mathrm{O}_{3}$ concentration elevated the risk of asthma significantly more than in the spring. Several studies have reported worse effects on ED visits due to asthma during the summer season [29,30]. In fall, ED visits for asthma were associated with $\mathrm{CO}, \mathrm{NO}_{2}, \mathrm{SO}_{2}$, and $\mathrm{PM}_{10}$ exposure. In winter, except patients exposed to $\mathrm{O}_{3}$ in the lag 1 model and in the cumulative lag 5 model, the risk for asthma ED visits was not significant regardless of air pollutants. This seasonal difference in risk may be explained by differences in exposure patterns; that is, in winter many people tend remain indoors, while in the warm season (spring and summer), people are more likely to engage in outdoor activities. However, because individual exposure level and susceptibility were not evaluated in this study, further studies are needed to better understand this issue [31].

A stratified analysis of prior allergic histories on ED visits for asthma showed an effect modification of pollutants on ED visits. With $\mathrm{O}_{3}$ or $\mathrm{PM}_{10}$ exposure, the risk of ED visits for asthma among those with a history of AD or AR was significantly higher than in participants without any history or participants with a history of asthma. The association between ED visits and IQR increases in $\mathrm{NO}_{2}, \mathrm{CO}$, and $\mathrm{SO}_{2}$ concentrations among individuals with a history of asthma was also higher than among those without any such history. In terms of the risk for asthma ED visits per IQR change in $\mathrm{O}_{3}$ concentration, no effect modification by prior allergic history was observed. These findings are consistent with those of another study that found that adult eczema was associated with more persistent asthma and asthma attacks [32]. The increased asthma exacerbation observed in the present study may suggest that atopic dermatitis could play a role in the mechanism of asthma attacks. Future studies are warranted to elucidate these points. A prospective population cohort study over four decades documented that $20 \%$ to $30 \%$ of cases of adult asthma with atopic characteristics were attributed to a history of eczema and rhinitis [33]. This result suggests that previous studies on the effects of atopic dermatitis and rhinitis on adult asthma may have underreported their findings due to regarding adult asthma as one condition rather than individual allergic characteristics [14].

The strengths of the present study include the stratification of the prior allergic histories of asthma patients, which could be a proxy for an analysis of the subtype of asthma (atopic or non-atopic). Additionally, we used data from national records, covering almost the entire Korean population, and the data on air pollutants and meteorological data had no missing values over the entire study period. Furthermore, subgroup analysis providing further insights into effect modifications may help improve the clinical applicability of our results. The results of the present study are supported by those of the most recent systematic review and meta-analysis [27]. In Korea, many studies have also documented the short-term exposure effects of daily pollutants on daily counts of ED visits in a given population, using a case-crossover study design $[34,35]$ or a generalized additive model with a Poisson distribution [36,37]. However, few studies have evaluated the effect modification of allergic history on the association between ambient air pollution and asthma ED visits. The result might contribute to predictive models of ED visits in the context of precision medicine.

The goal of the present study was to estimate the shortterm effect of air pollutants, and to specify the type of asthma with a higher risk of exacerbation, but our analysis does have some limitations. Without the residential addresses of patients, we averaged the exposure data into a daily mean concentration on the district level, which may not account for individual variation in exposure due to local sources of exposure, air conditioning systems, ventilation, or time spent outdoors. The HIRA data also incorporated no individual data regarding smoking or drinking history, socioeconomic status, or psychological stress, which has been associated with AD and AR as well as asthma in adults. Subgroup analysis was performed to verify the robustness of the main findings. Furthermore, the current study design used single-pollutant models. Multiplepollutant models would elucidate the joint effect of pollutants on adverse health outcomes [38]. This study also has a limitation stemming from the potential misclassification of asthma ED visits, since they were defined only by the discharge diagnosis code without pulmonary functional test results. For example, multiple ED visits could include asthma patients who sought care to obtain prescriptions for asthma but did not show symptoms.

In conclusion, IQR increases in ambient air pollutants were positively associated with ED visits for asthma. After stratification by prior allergic disease, the strongest statistically significant risk was observed among subjects with a prior history of $A D$ or $A R$ who were exposed to $\mathrm{O}_{3}$ or $\mathrm{PM}_{10}$.

\section{CONFLICT OF INTEREST}

The authors have no conflicts of interest associated with the material presented in this paper. 


\section{ORCID}

Juhwan Noh http://orcid.org/0000-0003-0657-0082

Changsoo Kim http://orcid.org/0000-0002-5940-5649

\section{REFERENCES}

1. Oh IH, Yoon SJ, Kim EJ. The burden of disease in Korea. J Korean Med Assoc 2011;54(6):646-652 (Korean).

2. OECD. Health at a glance 2013: OECD indicators [cited 2016 Sep 16]. Available from: http://apps.who.int/medicinedocs/ documents/s21725en/s21725en.pdf.

3. Korean Academy of Asthma, Allergy and Clinical Immunology; Korean Academy of Pediatric Allergy and Respiratory Disease; National Strategic Coordinating Center for Clinical Research. Korean guideline for asthma; 2015 [cited 2016 Sep 16]. Available from: http://www.allergy.or.kr/file/150527_01. pdf.

4. Kim SY, Jung JY, Park MS, Kang YA, Kim EY, Kim SK, et al. Increased prevalence of self-reported asthma among Korean adults: an analysis of KNHANES I and IV data. Lung 2013; 191(3):281-288.

5. Clark NA, Demers PA, Karr CJ, Koehoorn M, Lencar C, Tamburic $L$, et al. Effect of early life exposure to air pollution on development of childhood asthma. Environ Health Perspect 2010; 118(2):284-290.

6. Jacquemin B, Sunyer J, Forsberg B, Aguilera I, Briggs D, GarcíaEsteban R, et al. Home outdoor NO2 and new onset of self-reported asthma in adults. Epidemiology 2009;20(1):119-126.

7. Jerrett M, Shankardass K, Berhane K, Gauderman WJ, Künzli N, Avol E, et al. Traffic-related air pollution and asthma onset in children: a prospective cohort study with individual exposure measurement. Environ Health Perspect 2008;116(10):14331438.

8. Bowatte G, Lodge C, Lowe AJ, Erbas B, Perret J, Abramson MJ, et al. The influence of childhood traffic-related air pollution exposure on asthma, allergy and sensitization: a systematic review and a meta-analysis of birth cohort studies. Allergy 2015;70(3):245-256.

9. Peden D. Air pollution and asthma. In: Nadadur SS, Hollingsworth JW, editors. Air pollution and health effects. Heidelberg: Humana Press; 2015, p. 93-117.

10. Weinmayr G, Romeo E, De Sario M, Weiland SK, Forastiere F. Short-term effects of PM10 and NO2 on respiratory health among children with asthma or asthma-like symptoms: a sys- tematic review and meta-analysis. Environ Health Perspect 2010;118(4):449-457.

11. Schildcrout JS, Sheppard L, Lumley T, Slaughter JC, Koenig JQ, Shapiro GG. Ambient air pollution and asthma exacerbations in children: an eight-city analysis. Am J Epidemiol 2006; 164(6):505-517.

12. Slaughter JC, Lumley T, Sheppard L, Koenig JQ, Shapiro GG. Effects of ambient air pollution on symptom severity and medication use in children with asthma. Ann Allergy Asthma Immunol 2003;91(4):346-353.

13. Gent JF, Triche EW, Holford TR, Belanger K, Bracken MB, Beckett WS, et al. Association of low-level ozone and fine particles with respiratory symptoms in children with asthma. JAMA 2003;290(14):1859-1867.

14. Bantz SK, Zhu Z, Zheng T. The atopic march: progression from atopic dermatitis to allergic rhinitis and asthma. J Clin Cell Immunol 2014;5(2):202.

15. Oh JW, Kim JH, Chang YS, Sohn KT. Development of binary forecast models of asthma exacerbation: asthma index. Eur Respir J 2014;44(Suppl 58):P4056.

16. Hastie T, Tibshirani R. Generalized additive models. London: Chapman and Hall; 1990, p. 82-103.

17. Wood SN. Generalized additive models : an introduction with R. Boca Raton: CRC Press; 2006, p.121-140.

18. Qiu H, Yu IT, Tian L, Wang X, Tse LA, Tam W, et al. Effects of coarse particulate matter on emergency hospital admissions for respiratory diseases: a time-series analysis in Hong Kong. Environ Health Perspect 2012;120(4):572-576.

19. Curriero FC, Heiner KS, Samet JM, Zeger SL, Strug L, Patz JA. Temperature and mortality in 11 cities of the eastern United States. Am J Epidemiol 2002;155(1):80-87.

20. Altman DG, Bland JM. Interaction revisited: the difference between two estimates. BMJ 2003;326(7382):219.

21. Kim J, Kim H, Kweon J. Hourly differences in air pollution on the risk of asthma exacerbation. Environ Pollut 2015;203:1521.

22. Strickland MJ, Klein M, Flanders WD, Chang $\mathrm{HH}$, Mulholland JA, Tolbert PE, et al. Modification of the effect of ambient air pollution on pediatric asthma emergency visits: susceptible subpopulations. Epidemiology 2014;25(6):843-850.

23. Burra TA, Moineddin R, Agha MM, Glazier RH. Social disadvantage, air pollution, and asthma physician visits in Toronto, Canada. Environ Res 2009;109(5):567-574.

24. Lavigne E, Villeneuve PJ, Cakmak S. Air pollution and emergency department visits for asthma in Windsor, Canada. Can J 
Public Health 2012;103(1):4-8.

25. Clougherty JE. A growing role for gender analysis in air pollution epidemiology. Environ Health Perspect 2010;118(2):167176.

26. Becklake MR, Kauffmann F. Gender differences in airway behaviour over the human life span. Thorax 1999;54(12):11191138.

27. Zheng XY, Ding H, Jiang LN, Chen SW, Zheng JP, Qiu M, et al. Association between air pollutants and asthma emergency room visits and hospital admissions in time series studies: a systematic review and meta-analysis. PLoS One 2015;10(9): e0138146.

28. Stieb DM, Szyszkowicz M, Rowe BH, Leech JA. Air pollution and emergency department visits for cardiac and respiratory conditions: a multi-city time-series analysis. Environ Health 2009;8:25.

29. Yi O, Hong YC, Kim H. Seasonal effect of PM(10) concentrations on mortality and morbidity in Seoul, Korea: a temperature-matched case-crossover analysis. Environ Res 2010; 110(1):89-95.

30. Son JY, Lee JT, Park YH, Bell ML. Short-term effects of air pollution on hospital admissions in Korea. Epidemiology 2013; 24(4):545-554.

31. Kim C, Jung SH, Kang DR, Kim HC, Moon KT, Hur NW, et al. Ambient particulate matter as a risk factor for suicide. Am J Psychiatry 2010;167(9):1100-1107.
32. Silverberg Jl, Hanifin JM. Adult eczema prevalence and associations with asthma and other health and demographic factors: a US population-based study. J Allergy Clin Immunol 2013;132(5):1132-1138.

33. Martin PE, Matheson MC, Gurrin L, Burgess JA, Osborne N, Lowe AJ, et al. Childhood eczema and rhinitis predict atopic but not nonatopic adult asthma: a prospective cohort study over 4 decades. J Allergy Clin Immunol 2011;127(6):14731479.e1.

34. Kim SY, Kim H, Kim J. Effects of air pollution on asthma in Seoul: comparisons across subject characteristics. J Prev Med Public Health 2006;39(4):309-316 (Korean).

35. Im HJ, Lee SY, Yun KJ, Ju YS, Kang DH, Cho SH. A case-crossover study between air pollution and hospital emergency room visits by asthma attack. Korean J Occup Environ Med 2000;12(2):249-257 (Korean).

36. Ju YS, Cho SH. Effect of air pollution on emergency room visits for asthma: a time series analysis. Korean J Prev Med 2001; 34(1):61-72 (Korean).

37. Lee JT, Kim H, Song H, Hong YC, Cho YS, Shin SY, et al. Air pollution and asthma among children in Seoul, Korea. Epidemiology 2002;13(4):481-484.

38. Winquist A, Kirrane E, Klein M, Strickland M, Darrow LA, Sarnat $\mathrm{SE}$, et al. Joint effects of ambient air pollutants on pediatric asthma emergency department visits in Atlanta, 1998-2004. Epidemiology 2014;25(5):666-673. 


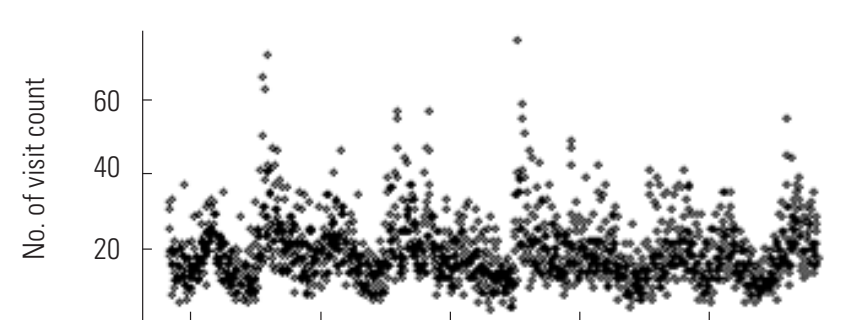

$\begin{array}{ccccc}05-01-01 & 06-01-01 & 07-01-01 & 08-01-01 & 09-01-01\end{array}$

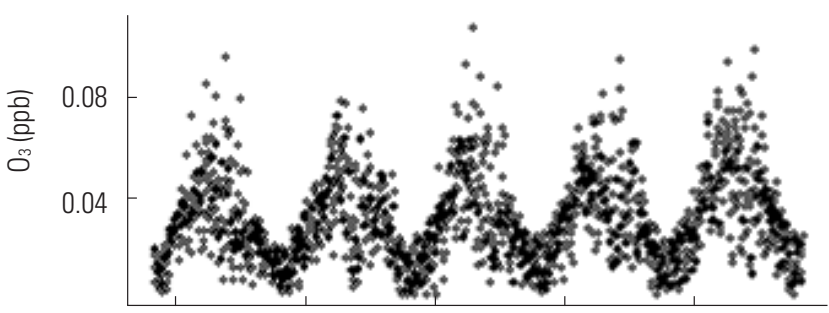

05-01-01 06-01-01 07-01-01 08-01-01 09-01-01 Time (2005.01.01-2009.12.31)

C

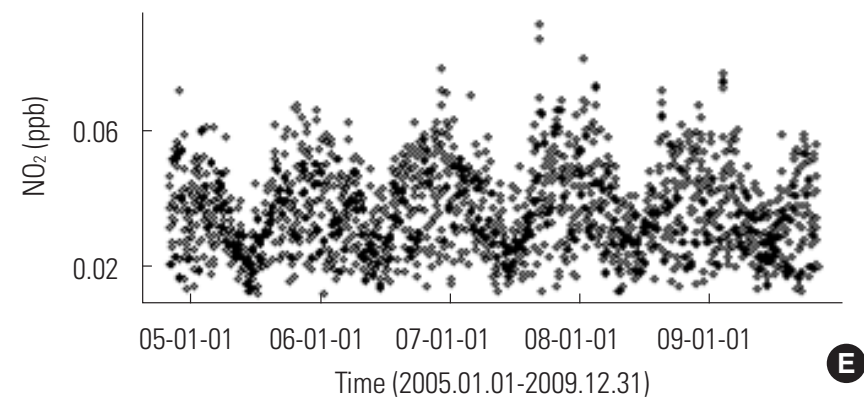

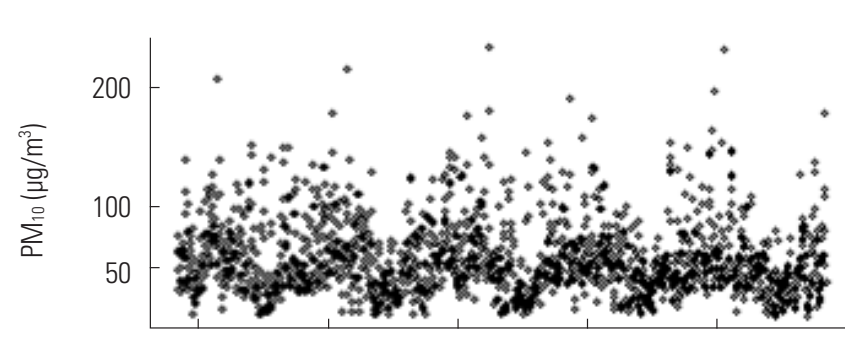

05-01-01 06-01-01 07-01-01 $08-01-01 \quad 09-01-01 \quad$ B Time (2005.01.01-2009.12.31)
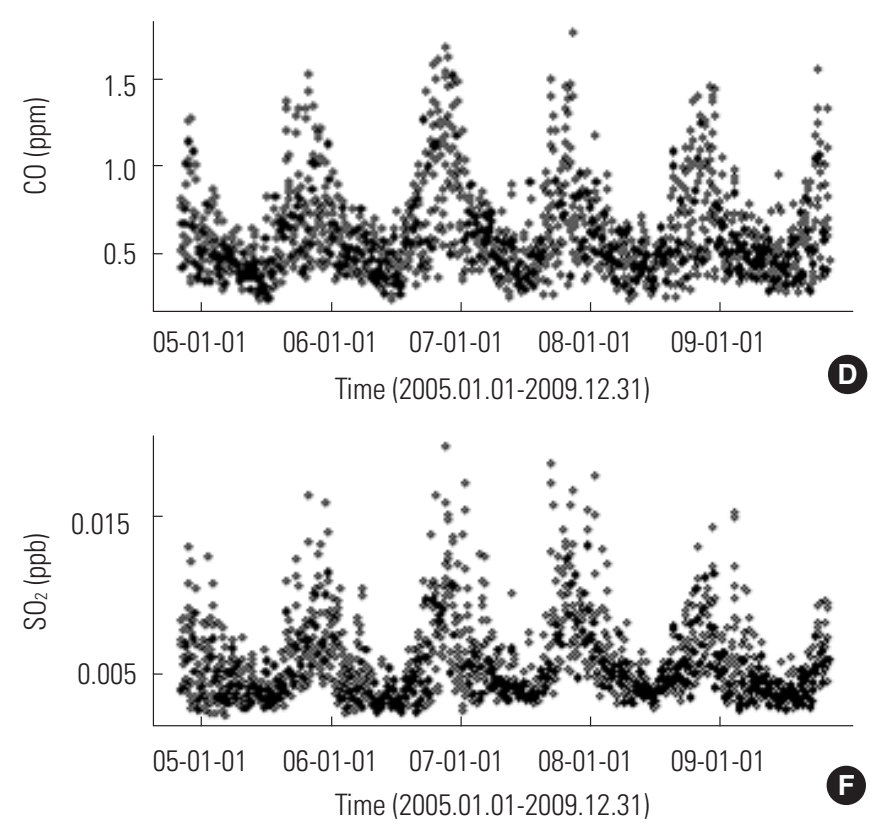

Supplemental Figure 1. Daily distribution of asthma emergency department (ED) visits, air pollutant concentrations, and relative humidity. (A) Number of ED visit due to asthma, air pollution concentration of (B) particulate matter with an aerodynamic diameter <10 $\mu \mathrm{m}\left(\mathrm{PM}_{10}\right)$, (C) ozone $\left(\mathrm{O}_{3}\right)$, (D) carbon monoxide $(\mathrm{CO})$, (E) nitrogen dioxide $\left(\mathrm{NO}_{2}\right)$, and $(\mathrm{F})$ sulfur dioxide $\left(\mathrm{SO} \mathrm{O}_{2}\right.$ ). 
Journal of

Preventive Medicine \& Public Health

Supplemental Table 1. Pearson correlation coefficients ${ }^{1}$ between pollutants and meteorological variables, Korea, January 2005 to December 2009

\begin{tabular}{|c|c|c|c|c|c|c|c|c|}
\hline & $\mathbf{O}_{3}$ & $\mathrm{CO}$ & $\mathrm{NO}_{2}$ & $\mathrm{SO}_{2}$ & $\mathrm{PM}_{10}$ & Temperature & Relative humidity & Vapor pressure \\
\hline $\mathrm{O}_{3}$ (8-hr maximum) & 1 & & & & & & & \\
\hline CO (daily mean) & -0.41 & 1 & & & & & & \\
\hline $\mathrm{NO}_{2}$ (daily mean) & -0.21 & 0.82 & 1 & & & & & \\
\hline $\mathrm{SO}_{2}$ (daily mean) & -0.24 & 0.79 & 0.71 & 1 & & & & \\
\hline $\mathrm{PM}_{10}$ (daily mean) & 0.05 & 0.43 & 0.4 & 0.43 & 1 & & & \\
\hline Temperature & 0.56 & -0.37 & -0.18 & -0.43 & -0.09 & 1 & & \\
\hline Relative humidity & -0.08 & -0.01 & -0.1 & -0.17 & -0.05 & 0.41 & 1 & \\
\hline Vapor pressure & 0.38 & -0.36 & -0.29 & -0.43 & -0.14 & 0.89 & 0.66 & 1 \\
\hline
\end{tabular}

$\mathrm{O}_{3}$, ozone; $\mathrm{CO}$, carbon monoxide; $\mathrm{NO}_{2}$, nitrogen dioxide; $\mathrm{SO}_{2}$, sulfur dioxide; $\mathrm{PM}_{10}$, particulate matter with an aerodynamic diameter $<10 \mu \mathrm{m}$.

${ }^{1}$ Correlation coefficients were significant $(p<0.001)$, except for the correlation between relative humidity and $\mathrm{CO}$. 